\title{
Espaços, mobiliário escolar e práticas culturais no Ginásio Sagrado Coração de Senhor do Bonfim - BA (1951)
}

\author{
Virgínia Pereira da Silva Ávila' \\ Nilton Ferreira Bittencourt Junior ${ }^{2}$ \\ Dulcineia Cândida Cardoso de Medeiros ${ }^{3}$
}

\section{RESUMO}

Este texto analisa o papel atribuído aos espaços, ao mobiliário escolar e às práticas culturais no relatório de verificação do Ginásio Sagrado Coração, localizado em Senhor do Bonfim - BA. Organizado pelo inspetor Othoniel Almeida Moura, em 1951, o relatório registra a história da instituição, mas também apresenta as marcas e a significação do momento histórico e político vivenciado na sociedade brasileira. O relatório possui 110 páginas e contém dados sobre o histórico do estabelecimento, os aspectos relativos à estrutura física, a capacidade das salas, o corpo docente em exercício, a relação de livros da biblioteca, os materiais didáticos, a relação de materiais e os equipamentos de Educação Física, além de 26 fotografias. Composto de 07 (sete) divisões, nele são expostos e avaliados de maneira pormenorizadas, numa escala de 0 a 10 (dez), diversos aspectos referentes à localização, ao edifício, às instalações, às salas de aula, às salas especiais e os materiais didáticos, às instalações

1 Doutora em Educação Escolar pela Universidade Estadual Paulista Júlio de Mesquita Filho (UNESP). Pós-doutora em História da Educação pela Universidade de Lisboa. Professora da Universidade de Pernambuco (UPE), Campus Petrolina. Membro do Colegiado de Pedagogia e no Programa de Pós-Graduação em Formação de Professores e Práticas Interdisciplinares. Membro do Conselho Editorial da Editora da Universidade de Pernambuco - EDUPE. Coordena o Núcleo de Extensão e Pesquisas em História, Educação, Linguística e Literatura (NEPHEL). Colabora como investigadora nas áreas da educação e na implantação de projetos de educação na Escola Superior de Educação e Ciências Sociais (ESECS) do Politécnico de Leiria, Portugal. ORCID: https://orcid.org/0000-0002-2634-1474. E-mail: virginia.avila@upe. br.

2 Doutor em Educação - PPGED - Universidade Federal de Uberlândia. Professor do curso de Pedagogia da Universidade Federal do Piauí - UFPI/CSHNB. Pesquisador na área de Educação. ORCID: http://orcid.org/0000-0002-2148-3828. E-mail: niltonbittencourt@ufpi.edu.br.

3 Especialista em Atendimento Educacional Especializado - Área de Concentração: Educação Especial pela Universidade Estadual de Maringá - Paraná. Graduação em Pedagogia pela Universidade do Estado da Bahia - Campus VII. Professora da Rede Pública Municipal de Senhor do Bonfim - Ba. ORCID: http://orcid.org/0000-0003-0650-2274.E-mail:dccmedeiros@ gmail.com. 
para semi-internato, às instalações para internatos. O texto dialoga com os estudos sobre cultura material, cultural escolar e patrimônio histórico-educativo. Autores como Benito (2012), Vinão Frago (2005), Castro e Gaspar da Silva (2011), Alcântara e Vidal (2018) e Rocha (2018) auxiliam na compreensão do patrimônio material escolar como o registro empírico e efetivo das práticas culturais "de uma época, de cada época, de todas épocas". Por fim, o estudo possibilitou o levantamento de hipóteses das práticas culturais desenvolvidas pela instituição, assim como a compreensão da utilização dos espaços e dos materiais seguindo os padrões nacionalmente estabelecidos.

Palavras-Chave: Ginásio. Fontes de pesquisa. História da Educação.

\section{Spaces, school furniture and cultural practices in the Sagrado Coração de Senhor do Bonfim gymnasium - BA (1951)}

\section{ABSTRACT}

This text analyzes the role attributed to spaces, school furniture and cultural practices in the verification report of the new facilities of the Ginásio Sagrado Coração, located in Senhor do Bonfim - BA. Organized by inspector Othoniel Almeida Moura, in 1951, the report records not only the history of the institution, but also presents the marks and the significance of the historical and political moment experienced in Brazilian society. The report has 110 pages and contains data on the history of the establishment, the aspects related to the physical structure, the capacity of the rooms, the teaching staff in office, the list of books in the library, the teaching materials, the list of materials and the equipment of Physical Education, in addition to 26 photographs. Composed of 07 (seven) divisions, it is exposed and evaluated in a detailed way, on a scale of 0 to 10 (ten), several aspects related to the location, the building, the facilities, the classrooms, the special rooms and the materials educational facilities, semi-boarding facilities, boarding facilities. The text dialogues with studies on material culture, school culture and historical-educational heritage. Authors such as Benito (2012), Vinão (2005), Castro and Gaspar da Silva (2011), Alcântara and Vidal (2018) and Rocha (2018) help to understand school material heritage as the empirical and effective record of cultural practices "of one season, each season, all seasons". Finally, the study made it possible to raise hypotheses about cultural practices developed by the institution, 
as well as to understand the use of spaces and materials following nationally established standards.

Keywords: Gymnasium. Search sources. History of Education.

\section{Espacios, mobiliario escolar y prácticas culturales en el gimnasio Sagrado Coração de Senhor do Bonfim - BA (1951)}

\section{RESUMEN}

Este texto analiza el papel atribuido a los espacios, el mobiliario escolar y las prácticas culturales en el informe de verificación de las nuevas instalaciones del Ginásio Sagrado Coração, ubicado en Senhor do Bonfim - BA. Organizado por el inspector Othoniel Almeida Moura, en 1951, el informe registra no solo la historia de la institución, sino que también presenta las marcas y la importancia del momento histórico y político experimentado en la sociedad brasileña. El informe tiene 110 páginas y contiene datos sobre la historia del establecimiento, los aspectos relacionados con la estructura física, la capacidad de las habitaciones, el personal docente en la oficina, la lista de libros en la biblioteca, los materiales de enseñanza, la lista de materiales y el equipo. de Educación Física, además de 26 fotografías. Compuesto por 07 (siete) divisiones, se expone y evalúa de manera detallada, en una escala de 0 a 10 (diez), varios aspectos relacionados con la ubicación, el edificio, las instalaciones, las aulas, las salas especiales y los materiales, instalaciones educativas, instalaciones de semi-embarque, instalaciones de embarque. El texto dialoga con estudios sobre cultura material, cultura escolar y patrimonio histórico-educativo. Autores como Benito (2012), Vinão (2005), Castro y Gaspar da Silva (2011), Alcântara y Vidal (2018) y Rocha (2018) ayudan a entender el patrimonio material escolar como el registro empírico y efectivo de las prácticas culturales "de una temporada, cada temporada, todas las estaciones". Finalmente, el estudio permitió plantear hipótesis sobre las prácticas culturales desarrolladas por la institución, así como comprender el uso de espacios y materiales siguiendo estándares establecidos a nivel nacional.

Palabras clave: Gimnasio. Buscar fuentes. Historia de la educación. 


\section{Introdução}

Como refere Mogarro (2005), os documentos escolares, quando transformados em fontes, permitem análise dos vários discursos produzidos pelos "actores educativos". Além disso, são portadores de informações que trazem, do passado até o presente, vários aspectos da vida escolar, considerados patrimônio educativo de cada instituição, ocupando lugar de destaque na reconstrução do itinerário da instituição escolar. Esses documentos registram não somente a história da instituição, mas também apresentam as marcas e a significação do momento histórico e político vivenciado na sociedade brasileira. É o caso dos relatórios de inspeção escolar do Ginásio Sagrado Coração, situado no município de Senhor do Bonfim, no estado da Bahia, escritos pelo inspetor Othoniel Almeida Moura, no período entre os anos de 1944 a 1954.

Neste trabalho, destaca-se o relatório de verificação das novas instalações do Ginásio Sagrado Coração, compilado em livro, datado de 1951, endereçado à professora Lúcia Magalhães, Diretora do Ensino Secundário do Ministério da Educação e Saúde. O relatório possui 110 páginas e contém dados sobre o histórico do estabelecimento, os aspectos relativos à estrutura física, a capacidade das salas, o corpo docente em exercício, a relação de livros da biblioteca, os materiais didáticos, a relação de materiais e de equipamentos de Educação Física, além de 26 fotografias, das quais somente 24 se encontram afixadas nas suas páginas. Aos itens são atribuídas notas 0 a $10^{4}$.

O Ginásio Sagrado Coração iniciou o seu funcionamento no ano de 1944, na cidade de Senhor do Bonfim, no interior da Bahia. De propriedade da Ordem dos Irmãos Maristas, funcionava em regime de internato e semi-internato, exclusivamente para meninos. Esta escola passou por uma transformação no início da década de 1950, com a construção de um novo prédio e com a adequação a um modelo pedagógico moderno. Por ocasião da mudança para novas instalações, ocorrida em 1951, o inspetor Othoniel Almeida Moura realizou a inspeção preliminar do estabelecimento, produzindo o Relatório de verificação das novas instalações do Ginásio Sagrado Coração.

No decorrer do relatório, o inspetor apresenta algumas justificativas para as notas atribuídas, a exemplo de as salas de línguas vivas e a

4 A esse respeito, ver Medeiros e Ávila (2020). Nesse estudo, as autoras analisam os relatórios de inspeção do inspetor Othoniel Almeida Moura. 
sala de trabalhos manuais, que ainda não se encontravam construídas, dispondo apenas dos materiais. Justifica-se também a nota atribuída às carteiras que se apresentavam duplas e individuais, relatando o inspetor que "Pretende o ginásio, renovar, em futuro próximo, o mobiliário atual, a fim de uniformizá-lo com carteiras individuais" (MOURA, 1951, p. 8).

Ao analisar o Relatório de verificação das novas instalações do Ginásio Sagrado Coração, logo nas primeiras páginas é exposto o objetivo da instituição: “[...] destina-se à instrução primária e secundária da juventude, segundo os moldes dos programas oficiais do Colégio Pedro II do Rio de Janeiro" (MOURA, 1951, p. 3). O Colégio Pedro II do Rio de Janeiro era referência para a nação. Criado pelo governo imperial em 1837, o Colégio Pedro Il permanece em funcionamento após a República, sendo mantido pelo Governo Federal, conservando, até meados do século $X X$, o caráter de instituição modelar para todo o ensino secundário brasileiro (MENDONÇA, 2013 et al.). Há de se destacar também o pensamento pedagógico que circulava no Brasil e no mundo, no período que antecede a criação do Ginásio Sagrado Coração no interior da Bahia, e que possivelmente influenciou na organização dos espaços e do mobiliário escolar.

Diante disso, indaga-se: Que condições materiais influenciaram e possibilitaram que o ensino ofertado no Ginásio Sagrado Coração seguisse os padrões estabelecidos no Colégio Pedro II? Como eram organizados os espaços no ambiente escolar? Quais modelos pedagógicos circulavam na proposição das novas instalações? Para responder a essas questões, analisam-se a estrutura física e o material da instituição e as notas atribuídas de 0 (zero) a 10 (dez), na ficha de classificação utilizada pelo inspetor Othoniel Almeida Moura. O parâmetro utilizado para a atribuição dessas notas, provavelmente, estava amparado na Portaria Ministerial $n^{\circ} 375$, de 16 de agosto de 1949, conforme relata o inspetor, quando faz referência à essa portaria. Declara também que o Ginásio estava cumprindo com as disposições legais vigentes, ministrando ensino eficiente e cumprindo o regimento interno.

Dos 40 itens avaliados pelo inspetor Othoniel Moura, na ficha de classificação básica, somente 12 não obtiveram nota 10 (dez). Apenas em um item não foi atribuída a nota, pois, referia-se ao auditório que ainda estava em construção. Os itens que não obtiveram avaliação máxima e sua respectiva nota foram: extintores de incêndio, 4 (quatro); número de salas de aula, 9 (nove); disposição das janelas das salas de 
aula, 8 (oito); carteiras, 5 (cinco); móveis diversos, 7 (sete); biblioteca, 7 (sete); sala de Geografia, 8,5 (oito e meio); sala de línguas vivas, 1 (um); sala de ciências, 7 (sete); sala de desenho, 9 (nove); sala de trabalhos manuais, 5 (cinco); e sala dos professores, 8 (oito). No decorrer do relatório, apresentam-se algumas justificativas para as notas atribuídas, a exemplo das salas de línguas vivas e a sala de trabalhos manuais, que ainda não se encontravam construídas, dispondo apenas dos materiais. Justifica-se também a nota atribuída às carteiras que se apresentavam duplas e individuais, relatando o inspetor que "Pretende o ginásio, renovar, em futuro próximo, o mobiliário atual, a fim de uniformizá-lo com carteiras individuais" (MOURA, 1951, p. 8).

O texto está organizado em três partes, compostas de uma introdução, de duas seções e de as considerações finais. A primeira seção, Pressupostos científicos e a organização dos espaços, dedica-se à análise dos itens do relatório, à verificação das instalações do Ginásio, bem como às notas atribuídas pelo inspetor, Othoniel Moura, e à sua relação com os preceitos médico-higienistas. Na segunda seção, A materialidade nas salas especiais de geografia e ciências, discute-se a disposição das salas especiais, incluindo o mobiliário e os materiais didático pedagógicos.

Por fim, o estudo aponta a necessidade de investigações mais aprofundadas com outros recortes temporais, a fim de ampliar o conhecimento sobre os usos dos espaços e do mobiliário e de sua repercussão nas práticas culturais no Ginásio Sagrado Coração.

\section{Pressupostos científicos e a organização dos espaços}

O relatório de verificação das instalações, produzido pelo inspetor Othoniel Moura, em 1951, inicia-se com um documento dirigido ao Ministério da Educação e Saúde, seguido de histórico do estabelecimento. Composto de 07 (sete) divisões, no relatório são expostos e avaliados de maneira pormenorizadas os diversos aspectos referentes à localização, ao edifício, às instalações, às salas de aula, às salas especiais e os materiais didáticos, às instalações para semi-internato, às instalações para internatos. Há uma seção dedicada à Educação Física em que são avaliados os itens referentes à área livre, às instalações, aos materiais desportivos, ao gabinete biométrico, ao vestiário e aos chuveiros. Apresenta também 60 anexos compreendidos entre fotografias, cálculos para atribuição das notas, relação de corpo docente, regulamento, "croquis". 
Na primeira Divisão, referente à localização, constam dados sobre salubridade, ausência de ruídos, ausência de perigos, causas perturbadoras de atenção, natureza e permeabilidade do terreno, regularidade do terreno, área coberta para recreio, área livre. Na segunda Divisão, referente ao edifício, encontram-se itens sobre a disposição interna, a situação, o número de pavimentos, o material de conservação, as entradas, as escadas e os corredores. O Ginásio obteve notas 10 em todos os itens. Para Vinão Frago (2005, p. 17), um dos elementos centrais

[...] na configuração da cultura escolar de uma determinada instituição educativa, juntamente com a distribuição e os usos do tempo, os discursos e as tecnologias da conversação e comunicação nela utilizados, é a distribuição e os usos do espaço, ou seja, a dupla configuração deste último como lugar e como território.

Na organização dos espaços do Ginásio Sagrado Coração de Senhor do Bonfim, a influência higienista se manifesta claramente na análise dos itens avaliados na terceira Divisão do relatório (extintores, caixa de água, instalações para limpeza geral do prédio, bebedouros, lavatórios, gabinetes, sanitários). Com exceção dos extintores aos quais foi atribuída a nota 4 (quatro), possivelmente em virtude da pequena quantidade, apenas 4 (quatro), os demais itens obtiveram nota 10 (dez). Chama a atenção a observação do inspetor no item instalações para limpeza geral do prédio, quando diz "não é possível utilizar aspiradores elétricos por não fornecer a Prefeitura Municipal energia elétrica durante o dia. A varredura é feita com panos umedecidos" (MOURA, 1951, p. 7). Embora esclareça que os aspiradores não são usados por falta de energia, não são expostas as quantidades desse item. Além dos aspiradores, constam 8 (oito) bebedouros automáticos, de jato lateral.

A quarta Divisão se refere as salas de aula, compostas dos seguintes itens: número de salas, área, forma, isolamento, quadros negros, pintura, área de iluminação, disposição das janelas, acústica, carteiras, móveis diversos. Aos aspectos estruturais apresentados, foram atribuídas notas 10, com exceção do número de salas, que obteve nota 9, e da disposição das janelas, nota 8. A estrutura física, por sua vez, foi motivo de elogios por parte do inspetor. Na maioria dos itens avaliados, no decorrer do relatório, foi atribuída a nota 10 . 
Com relação às carteiras escolares, de acordo com os estudos realizados por Vidal e Alcântara (2018), seus diferentes modelos exigiram, ao longo da história, uma diversidade de materiais e almejavam a diferentes corporeidades (postura correta ao sentar, ao ler, ao escrever, ao recitar) atreladas a modelos pedagógicos. No exame dessas autoras, o objetivo dos movimentos médico-higiênicos e pedagógicos, nas primeiras décadas do século, era que tais condutas fossem devidamente incorporadas pelos discentes. Todavia, elas ressaltam que esse movimento não era linear, referindo-se às singularidades dos discentes, que resultam em uma heterogeneidade de práticas corporais e o prescrito nos manuais, isto é, o que se almejava nem sempre se concretizava na prática. Com ênfase na disciplina e no controle dos corpos, o Estatuto do Ginásio Sagrado Coração de Bonfim estabelecia, entre as obrigações dos alunos, "estar atento durante as aulas e conservar-se numa postura digna" (GINÁSIO SAGRADO CORAÇÃO, 1944, p. 8).

No Ginásio Sagrado Coração, essas carteiras eram de dois tipos, individuais e em dupla. Na ficha de classificação, foi atribuída a nota 5 (cinco) para esse item, um indicativo de que as carteiras em dupla não satisfaziam aos padrões requeridos. No relatório consta que as carteiras duplas seriam trocadas por carteiras individuais. Neste aspecto, concorda-se com Castro e Gaspar da Silva (2011, p. 212) quando afirmam que,

\footnotetext{
"como parte integrante desta base material, as carteiras escolares não são dispostas ao acaso nas salas de aula. A disposição guarda intenções previamente estabelecidas, ou pela vontade do professor e acompanhada de métodos de ensino, manuais, regulamentos, ou por lei".
}

Vidal e Alcântara (2018) compartilham dessa ideia. Para elas, embora a mobília escolar apresente prescrições e guias, as apropriações e os usos desses materiais pelos sujeitos serão estabelecidas nas relações dinâmicas ocorridas na sala de aula.

A quinta Divisão do relatório de verificação das novas instalações do Ginásio Sagrado Coração compreendem as salas especiais e os materiais didáticos. Nessa divisão, foram avaliados o auditório, a biblioteca, a sala de Geografia, de Ciências, de Línguas Vivas, de Desenho, de Trabalhos Manuais, a sala dos professores, as salas da administração. Essa divisão apresentou lacunas, pois algumas dependências ainda estavam em construção (como o auditório), outras não construídas (como as 
Fotografia 1 - Carteira dupla e carteira simples individual, 1951.

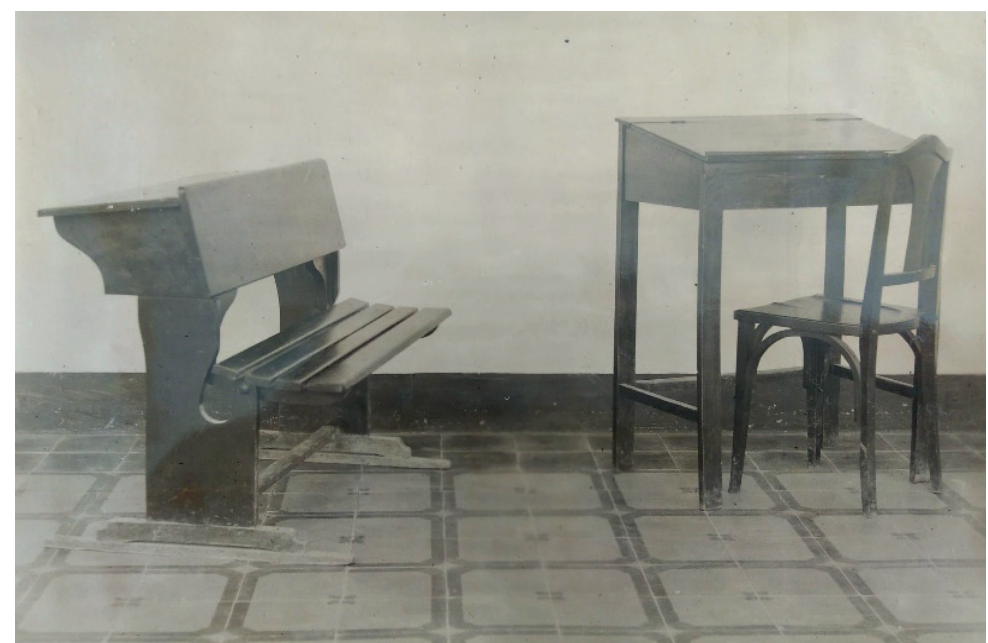

Fonte: Moura (1951, anexo 32)..

salas de línguas vivas e de trabalhos manuais) ou funcionando em locais provisórios (por exemplo, a biblioteca e as salas da administração). O inspetor Othoniel Moura fez alguns apontamentos sobre o auditório, que apresentava paredes erguidas já com 1,5m e com dimensões de $26 \mathrm{~m} x$ $10 \mathrm{~m}$; a biblioteca, que, embora funcionasse em sala provisória, recebeu elogios do inspetor, era bem organizada e de fácil acesso de docentes e de discentes, dispondo de livros de Religião, de História Geral e do Brasil, de Geografia Geral e do Brasil, de Matemática, de Ciências Naturais, de Inglês, de Latim, de Português, de Francês, de Física e de Química, de Desenho, de Música, de Pedagogia, de Dicionários e revistas, todos catalogados e discriminados no relatório; das salas não construídas - de Línguas Vivas e de Trabalhos Manuais, e a de Desenho (com a discriminação da relação dos materiais), sendo atribuídas respectivamente as notas 1 (um), 5 (cinco) e 9 (nove); a sala dos professores era arejada, com mobília confortável, poltronas, escrivaninhas e armários, e as 3 (três) salas da administração estava por inaugurar no decorrer do ano.

A sexta Divisão do relatório se destinava à avaliação das instalações para o semi-internato, abrangendo as seguintes dependências: refeitório, lavatório, cozinha, copa, despensa. Em todas as dependências avaliadas foi dada atenção especial aos aspectos relacionados à ventila- 
ção, à iluminação, ao piso, ao revestimento das paredes e aos materiais disponíveis. A análise das condições de higiene era perceptível e ainda mais enfática, quando expõe que as 6 (seis) pias do refeitório e as 2 (duas) pias da cozinha são com instalações de água fria e quente para esterilização das louças. $O$ inspetor Othoniel Moura esclarece ainda que talheres e copos eram de uso individual, os armários a prova de moscas e as latas para lixo dotadas de tampas.

Os preceitos higienistas e de cuidados com a saúde constituem a sétima Divisão do relatório de verificação das instalações, quando foram avaliados itens como dormitórios, instalações higiênicas, enfermaria e instalações diversas.

As duas áreas destinadas aos dormitórios mediam $280 \mathrm{~m}^{2}$ cada e comportavam 55 leitos. Obtiveram nota 7 (sete). Quanto às instalações higiênicas, os lavatórios foram classificados com nota 8 (oito) e os chuveiros, 9 (nove). Em todas as classificações referentes ao internato, as notas foram atribuídas fazendo-se cálculos que consideraram o número máximo de 110 alunos.

A enfermaria ainda estava em 'vias de conclusão', mas já apresentava alguns dados preliminares como piso ladrilhado, paredes revestidas de cimento branco, 10 camas de ferro esmaltado, banheiro de imersão com chuveiro, 2 (dois) banheiros individuais, 2 (dois) water closets (somente com pia e vaso) e todo o material próprio para pequenos curativos ou curativos de emergência. Em quarto contínuo, na enfermaria se localizavam o gabinete dentário, o qual deveria ser inaugurado simultaneamente com a fachada do edifício. $O$ inspetor não discrimina a lista de materiais do consultório dentário, mas observa que parte do material já existia no ginásio. Quanto à farmácia, destaca apenas que "existem medicamentos e materiais necessários a prestar os primeiros socorros" (MOURA, 1951, p. 13). A sua nota atribuída foi 10. Inseridas na ficha suplementar II, foram atribuídas à enfermaria as seguintes notas: pavimentação, nota 10 (dez); revestimento das paredes, 9 (nove); condições de isolamento, 10 (dez); e no item material e instalações não foi atribuída nota. Aos itens que não foram atribuídas notas, o inspetor justificou que, em verificações posteriores para o reconhecimento da instituição, seria realizado um exame mais aprimorado.

O relatório de verificação também apresenta uma seção destinada à Educação Física. No anexo 2 do relatório consta a lista de professores, sendo o de Educação Física, um militar. O setor contava com uma 
boa quantidade de materiais e de área livre disponível para as atividades físicas, perfazendo $8.400 \mathrm{~m}^{2}$. Nessa seção, consta a enumeração das instalações para a prática esportiva (caixa para saltos, aparelho para salto em altura, alvo para arremesso etc.), bem como as relações de materiais: bolas para diversas modalidades, medicine-balls, trena, cronômetro, cordas, fardos cilíndricos, redes, bastão para revezamento, discos, material de ping-pong, varas para salto, destacando-se que eram suficientes para o número de alunos.

Ainda na seção de Educação Física, o inspetor registrou aspectos referentes ao Gabinete Médico Biométrico, ao vestiário, aos chuveiros e algumas observações gerais sobre a instituição. Concernente ao Gabinete médico biométrico consta avaliação, porém sem atribuição de nota. De todo modo, é instalado em sala própria equipada com os seguintes materiais: uma fita métrica metálica de $2 \mathrm{~m}$; uma balança com precisão até 10gr; uma toesa para estatura e altura do busto; um espirômetro de água; um compasso de corrediça; um quadro mural de envergadura; um quadro mural para sentido muscular; um dinamômetro manual para criança; um dinamômetro manual para adultos; um dinamômetro para medida da força escapular; fichas médico-biométricas; mesa de exames clínicos; aparelhos de socorro de urgência.

Fotografia 2 - Gabinete Médico Biométrico, 1951.

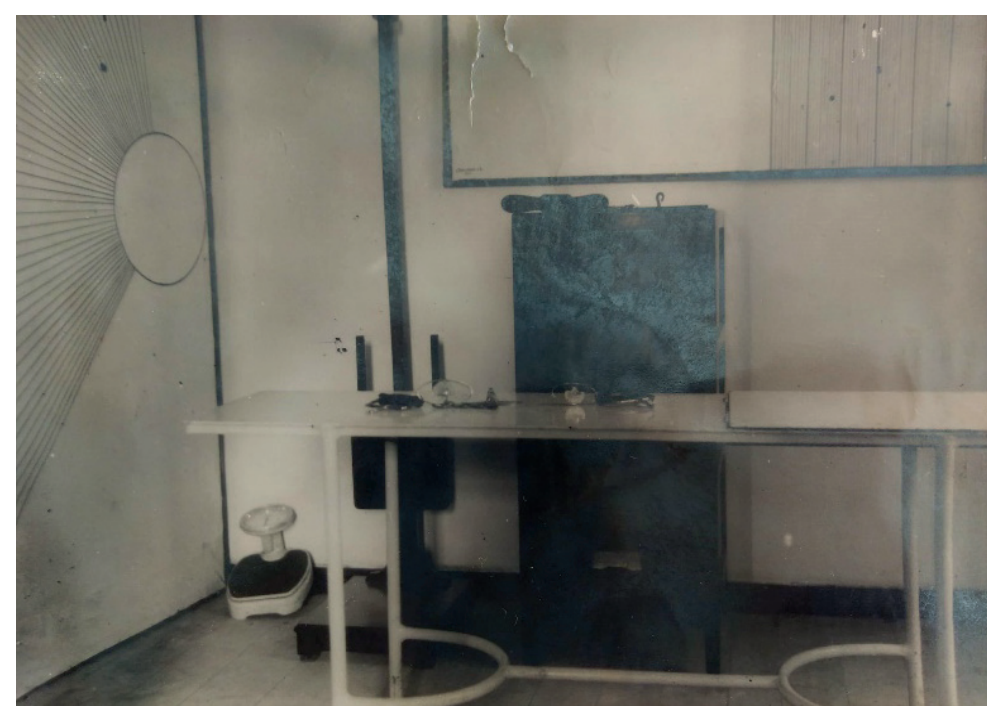

Fonte: Moura (1951, anexo 57). 
Em estudo realizado sobre a influência médico-higienista e a aquisição de instrumentos e equipamentos nas escolas primárias de São Paulo, nas primeiras décadas do século XX, Rocha (2018) aponta a importância da higiene na cultura material escolar paulista e apresenta fragmento do verbete Écolier (Hygiène de l'), do Dicitionnaire pratique de médecine et d'hygiene, de Desesquelle e Niewenglowski, publicado em Paris, em 1921, no qual Niewenglowsk aponta a necessidade de que, desde a entrada na escola, a criança seja examinada e as suas informações registradas em dossiê escolar.

Os objetos apresentados na lista do Gabinete médico biométrico do Ginásio Sagrado Coração e as indicações apresentadas pelos médicos franceses, em 1921, podem ser considerados vestígios da materialização das ideias disseminadas naquele período. Todos os materiais necessários para a avaliação dos alunos são apresentados na relação de materiais disponíveis no Ginásio. No Gabinete do Ginásio Sagrado Coração, eram registradas as fichas médico-biométricas. Nessas fichas, assinadas pelo médico, pelo inspetor federal e pelo professor de Educação Física, constavam dados do aluno (nome, sexo, data de nascimento, curso, série) e dados da instituição, espaços específicos para anotações do exame biométrico, exame clínico, dados etnológicos e exame prático.

Quanto ao vestiário, de dimensões $10 \mathrm{~m} \times 7 \mathrm{~m}$, era equipado com cabides e bancos que proporcionavam relativo conforto aos alunos, segundo o inspetor. O Ginásio dispunha de 22 chuveiros, todos individuais com piso ladrilhado revestido em azulejos brancos, até $1,30 \mathrm{~m}$ de altura.

De modo geral, o novo edifício obedecia aos critérios de conforto, de higiene e de cientificidade, evidenciando a importância do estudo dessa materialidade para a compreensão das práticas culturais de uma época. Como lembra Escolano (2012), a escola tem sido e é um lugar de produção de cultura. Esta cultura se traduz nas práticas em que se operacionalizam os processos formativos. As ações se materializam nos espaços, nos objetos, nas fotografias e nos textos que formam parte do patrimônio histórico-educativo.

\section{A materialidade nas salas especiais de geografia e ciências}

No Relatório de Verificação das novas Instalações do Ginásio Sagrado Coração, realizado pelo Inspetor Othoniel Almeida Moura, no ano de 1951, também podemos encontrar a descrição, tanto dos aspectos 
arquitetônicos do prédio, da disposição de salas de aula, dos pátios, dos auditórios, quanto na introdução de salas especiais, incluindo materiais didático pedagógicos.

Além das salas de aulas regulares e do auditório e biblioteca, o relatório cita a existência de 5 salas especiais. Podemos verificar que Bocchi (2020), no estudo sobre a reforma e a adequação do Colégio Marista Arquidiocesano de São Paulo, cita as salas especiais de ensino como parte no processo de adequação aos princípios pedagógicos do Colégio Pedro II. Estas salas são caracterizadas pela racionalidade da pedagogia moderna, ambientadas com equipamentos didáticos próprios da Matéria (disciplina) a ser ensinada, conforme o Método Intuitivo escolanovista. No relatório, o Inspetor Othoniel relata que algumas dessas salas estavam em construção e outras já prontas e equipadas com diversos materiais pedagógicos. As salas prontas e equipadas eram as Salas de Geografia, de Ciências e de Desenho. Em construção, estavam a Sala de Línguas vivas e de Trabalhos manuais. De modo especial, centramo-nos na descrição e na análise das salas especiais 'em atividade' de Geografia e de Ciências.

No anexo 35 do relatório do Inspetor Othoniel, no item 34 se observa a intencionalidade das proposições pedagógicas no detalhamento da materialidade da sala especial de ensino de Geografia. Na relação de material, há objetos como Globo terrestre, telúrio, Carta celeste, tabuleiro de areia, bússola, termômetro, cartas murais, atlas, amostra de produtos e coleção de vistas.

Quando o foco é a aplicação dos princípios da racionalidade pedagógica utilizadas na sala especial de ensino de Geografia do Ginásio Sagrado Coração, podemos perceber que obedece a alguns dos princípios adotados no Colégio Pedro II, universalizados na década de 1930, com a publicação do Manifesto dos Pioneiros da Educação Nova, em 1932. Nesse manifesto foram difundidos os princípios pedagógicos "[...] de adequar o ensino à fase de desenvolvimento mental do aluno, tornando-a prática através da obrigação do professor em dar exemplos brasileiros dos fenômenos estudados e da presença dos vários ramos dessa ciência." (COSTA, 2011, p. 274). No Ginásio Sagrado Coração, a sala especial de geografia também acompanha estas mudanças, que já ocorriam com maior ou menor intensidade, em diferentes regiões do país.

Interessa-nos entender a relação dos objetos relacionados no anexo 35 do relatório do Inspetor Othoniel, a partir da utilização pedagógica dos objetos geográficos, como a cartografia, descrita por Delga- 
do de Carvalho ${ }^{5}$, e a possibilidade de aplicação para a compreensão da identidade regional, entre outras questões pedagógicas propostas por ele, e a sua utilização no Ginásio Sagrado Coração. No entendimento de Costa (2011, p.272),

Para atingir tal objetivo, Delgado de Carvalho acreditava ser necessária a elaboração de uma metodologia para a disciplina na qual o espaço tinha um papel privilegiado. Em espaço adequado, os alunos se sentiriam mais motivados, ficariam mais concentrados e conseguiriam se integrar.

Se comparado aos instrumentos e objetos elencados por Delgado de Carvalho, pode-se dizer que havia a intenção do Ginásio Sagrado Coração em trabalhar o tema de climatografia, quando se observa a existência de material de meteorologia (termômetro e barômetro) e de orientação espacial como bússolas. Segundo Costa (2001, p. 277), “Dessa maneira, poderiam ser feitas experiências com o objetivo de explicar fenômenos geográficos, como a formação do dobramento do relevo e o achatamento dos polos".

Fotografia 3 - Sala de Geografia, 1951.

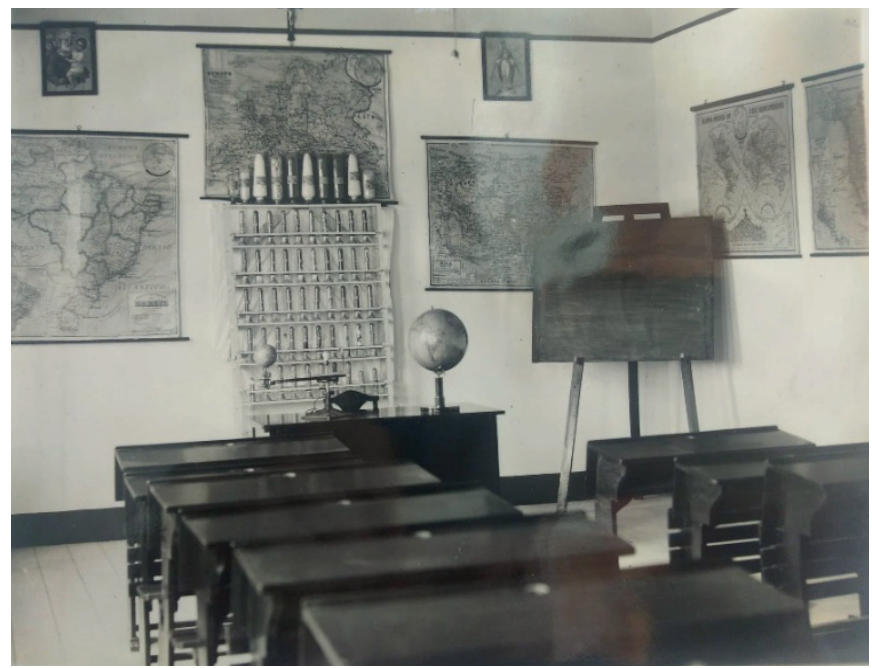

Fonte: Moura (1951, anexo 36).

5 Intelectual de formação francesa, chegou ao Brasil em 1906. Francês de nascimento, filho do embaixador do império brasileiro na França, só conheceu o Brasil aos 23 anos, sem inclusive falar a língua portuguesa, pois seu pai, após o fim do império, desgostou do Brasil e nunca retornou. 
No anexo 36, é visível um modelo, composto de esferas e de engrenagens, possivelmente para reproduzir os movimentos (rotação, revolução, translação) de corpos celestes (Terra; Lua; Sol), utilizado na exposição do comportamento real deste sistema e seu envolvimento no entendimento das estações do ano, por exemplo. Para além deste exemplo de possibilidade de uma aula expositiva com o auxílio de objetos didáticos, não é possível concluir se esses objetos eram para exposição, experimentação e/ou manipulação pelos discentes. O mesmo ocorre na relação de objetos pedagógicos do anexo 36, em que nada consta a respeito da quantidade de utilização de cada instrumento/objeto. Todavia, pode-se inferir que havia um conjunto de intencionalidades, em consonância com os princípios de racionalização da educação moderna, na época. Delgado de Carvalho, citado por Costa (2011), via nesta possibilidade de manipulação dos objetos, pelos discentes, o dinamismo de tornar real o conhecimento geográfico. Segundo ele, "Os murais deveriam ser amplos e conter não só mapas, mas também fotos, ilustrações, recortes de jornal, enfim, tudo que atribuísse "impressão de vida, de trabalho em curso e de atividades várias" (CARVALHO, apud COSTA, 2011, p. 277). Este será um ponto importante no novo processo didático de aprendizado da Geografia.

Ao observar a fotografia 3, a disposição das carteiras dos alunos está em fila indiana, diferindo-se do recomendado nos estudos sobre estas salas no Colégio Pedro II. Sobre essa questão, Costa (2011, p. 277) recorre a Zarur, quando este explica que disposição das carteiras deveria ser em "U" (semi-círculo), facilitando, desse modo, as aulas, a partir da demonstração de uso dos instrumentos/materiais. Isto permitiria a observação de objetos disponibilizados em vários pontos da sala, retirando o foco central da mesa do professor. Como bem disse,

Tal disposição das carteiras também facilitaria a observação do globo terrestre, que deveria estar suspenso e iluminado, mas ao alcance dos alunos. Sempre que solicitado, o professor deveria colocá-lo ao contato das mãos dos estudantes [...] (COSTA, 2011, p. 277).

Além das carteiras em fila indiana, nota-se que a mesa que existe na sala de aula é idêntica à existente em outras salas, não havendo diferenciação quanto ao seu uso para estudo de mapas, ou para a elaboração de plantas baixas pelos alunos. Isto dificultaria a elaboração de 
atividades práticas de Cartografia, ponto básico nas observações didático-pedagógica dos trabalhos com cartas (mapas) na matéria de Geografia. Acerca dessa questão,

Delgado de Carvalho salienta que, para entender a proporção utilizada nos mapas, era necessário que se aplicasse o exercício de reprodução de plantas. Utilizando o papel quadriculado sobre a mesa ao invés do quadro-negro, a criança compreenderia com muito mais facilidade (COSTA, 2011, p. 273).

Para Delgado de Carvalho, o aluno deveria fazer diversas plantas baixas, da sala de aula, do pátio escolar, da escola, do bairro da escola, e assim por diante em um movimento de irradiação do conhecimento geográfico.

Outro componente encontrado no Relatório de verificação das novas dependências do Ginásio Sagrado Coração, de autoria do Inspetor Federal Otoniel, é a Sala de Ciências. Acompanhando o princípio modernizador de criação de salas especiais, o anexo 38 registra a relação do material existente na sala de ciências, e os anexos 39 e 40 registram fotografias retratando esta sala.

Fotografias 4 e 5 - Sala de Ciências
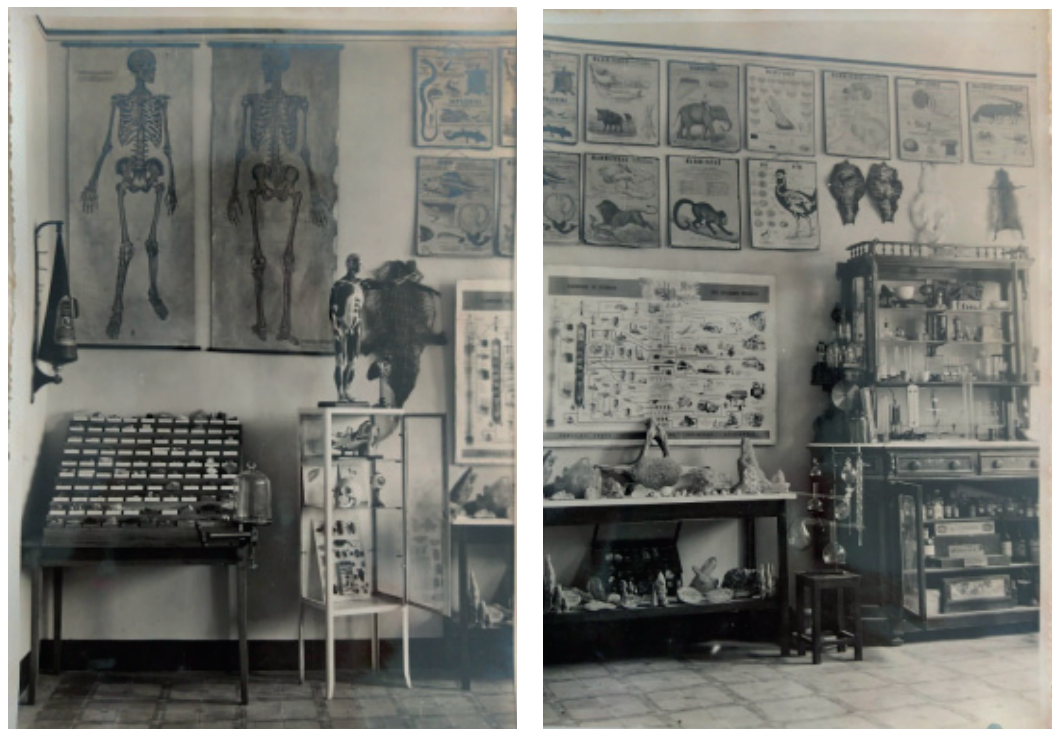

Fonte: Moura (19 51, anexo 39 e 40). 
Nas fotografias 4 e 5, podemos ver retratadas a Sala de Ciências. Na primeira fotografia, verificam-se dois quadros afixados na parede que retratam, de forma esquemática, o esqueleto humana (frente e costas) e outros quadros, demonstrando esquematicamente o interior de um peixe, uma raia e outros peixes que não foram possíveis identificar. Em outro quadro, há o esquema de répteis e batráquios. Em um armário de vidro, há objetos artificiais anatômicos dos seres humanos (olho, ouvido, crânio) e uma coleção de insetos. Sobre este armário, um boneco 'esfolado ${ }^{6 \prime}$ do ser humano e um objeto (aparentemente um órgão humano). Em uma bancada expositora, há uma coleção com nomes, porém de difícil identificação na foto. Ainda há equipamento fixado a esta bancada que aparenta ser um desidratador botânico. Acima, um objeto cilíndrico-coniforme afixado na parede (não identificada a nomenclatura e sua função). Também o couro de um jacaré afixado na parede.

A segunda fotografia é a continuação da primeira foto, pois retrata objetos e mobiliários que se encontram recortados na lateral da fotografia anterior. Nesta fotografia, identificaram-se outros dois mobiliários com materiais: uma mesa em que se pode ver sobre ela rochas diversas e uma vértebra de animal de grande porte. Este objeto não consta na relação do anexo 38. Tudo leva a crer que se trata de uma vértebra de um cetáceo ou ainda a possibilidade de ser um grande réptil fossilizado, uma vez que o município tem um grande sítio arqueológico próximo a sua região, no município de São Raimundo Nonato - PI. Na relação consta a existência de peixes fossilizados. Embaixo da mesa, há uma prateleira expondo uma diversidade de rochas e cristais.

A fotografia 5 apresenta um armário em duas partes (bancada e armário superior), composto por equipamentos de química e de física. Há uma vidraria que lembra uma botica antiga, além de tubos de ensaio, "caixas kosmos" de equipamentos (kits) didáticos de ensino de Ciências, termômetro, espectrômetro, cadinhos e balanças. Ao lado, sobre um banco de madeira, há um suporte com vários balões de ensaio.

Na parede, há afixado um grande quadro retratando esquematicamente alguns processos de industrialização, desde a extração de matéria-prima até a confecção de aparatos tecnológicos. Há também couro de animais (aparentemente de duas cobras e um mamífero) e nove quadros menores com esquemas - Coleções de classes biológicas (galiná-

6 Molde do corpo humano sem a cobertura da pele. 
ceos, crustáceos etc.). Também se verifica entre as peles de animais um objeto branco afixado, possivelmente outra pele de animal.

Não foram observados no relatório as dimensões desta sala. Acredita-se que acompanhava a dimensão de $8 \times 6,5$ metros, pois essa era a dimensão da maioria das salas do novo prédio. No relatório, a avaliação das instalações da sala relaciona os itens para o uso pedagógico de ensino de Ciências, como mesa de laboratório com pedra mármore, instalação elétrica, dispositivo para escurecer a sala, mesa para microscópio, quadro negro, quadros, murais, entre outros.

Na relação de material, há uma lista de 64 itens, denominados "Materiais de demonstração", porém sem a quantidade de cada item. $\mathrm{O}$ que nos leva a pensar novamente sobre como estes materiais eram utilizados durante as aulas, se eram para exposição, apresentação de experimentação e/ou para a manipulação de objetos pelos alunos. Deduzimos que este material foi classificado em 49 itens de equipamentos pedagógicos, entre os quais: microscópio, espectroscópio, esfolado completo, lâmpada dos mineiros", termômetros, 11 itens de "coleções" físicas ou retratadas em quadros (carpoteca, insecta, moluscos, vermes, pequeno herbário, peixes fósseis etc.) e 5 quadros (sendo 1 de esqueletos em que se lê quadros, supondo que são mais de 1, esqueleto de ave, esqueleto de crânio de carnívoro e 2 de coleções de classes biológicas). Em outra lista, encontram-se 32 itens denominados no relatório com "Material de experimentação" (cadinhos diversos, tubos de ensaio, tripés, buretas, pipetas etc.) e, por fim, uma lista denominada "Reagentes" com 65 itens (ácidos, sulfatos, óxidos etc.).

Ao comparar a relação de material no anexo 38 com as fotografias nos anexos 39 e 40, identificamos 14 quadros em exposição nas fotografias e não 5 como relatado na lista. Ainda podemos entender que as coleções são partes de objetos retratados em quadros e que há, na retratação, duas coleções físicas (uma na bancada do anexo 39, que pode ser a referência de 'pequeno herbário' e outra de rochas e fósseis. Além do já citado objeto, "vértebra animal de grande porte" que não consta na relação de itens do anexo 38 .

Outro fato que nos chama a atenção é a ausência de retratação dos mobiliários de adequação para a sala especial de Ciências, que é ci-

7 Equipamento usado em minas, que consiste em um tanque onde se colocam carbureto e água. A reação produz metano, que alimenta uma chama próxima de um pequeno espelho, em um dispositivo afixado na cabeça do mineiro. 
tado no início do relatório 38. Não foi possível verificar nas fotografias a existência de mesas (com pedra de mármore e para microscópio), disposição ou mesmo as carteiras, quadro negro e mesa do professor, e dispositivos para escurecer a sala. Estas discrepâncias entre os anexos podem ter ocorrido devido a falhas e a limitações na elaboração do relatório.

Da forma como consta no relatório do Inspetor Othoniel, é possível perceber a intencionalidade pedagógica de adotar o método intuitivo, como a lição das coisas e o uso de objetos didáticos científicos. Como se trata de um relatório sobre a verificação das novas instalações, fica clara esta intenção.

A questão da existência da sala especial de ensino de Ciências é uma intencionalidade de prática destes princípios pedagógicos. Mas faltam elementos para confirmar se o instituído ocorria. Alguns indícios apontam para a adaptação a uma realidade de salas especiais de ensino. $O$ próprio Delgado de Carvalho, nos anos 1950, aponta algumas críticas para a difusão dos princípios pedagógicos em sala-ambiente de Geografia:

[...] Delgado de Carvalho faz um balanço dos empecilhos mais encontrados à realização de sua proposta de sala ambiente, apresentada por ele pela primeira vez ainda na década de 1920: os horários, o tamanho das turmas, os extensos programas. E alerta para uma prática de certos colégios: "acumulam grande riqueza de material que só se acha aí 'para inglês ver', pois é julgado imprudente o professor que dele se quer utilizar em aula. Abundância de material não é sinônimo de ensino eficiente" (CARVALHO apud COSTA, 2011, p. 278).

Para Delgado, a sala-ambiente é uma metodologia em que o espaço tem lugar privilegiado. O ideal do ensino de Geografia é que os alunos pudessem viajar por todas as regiões do país. Como refere Costa (2011, p. 275), “Na impossibilidade disso, a sala de aula deveria fornecer recursos didáticos que permitissem tal exercício. Nesse aspecto, tal espaço deveria se diferenciar de qualquer outro da escola, começando pela própria denominação: sala-ambiente ou gabinete de geografia.".

Entendemos que estes objetos são auxiliares no processo educativo, devendo, assim, o professor atuar no planejamento de utilização deles. Estar em uma sala-ambiente sem um projeto de sua utilização não faz parte da transformação educativa proposta. É essa nossa intenção na análise do mobiliário do Ginásio Sagrado Coração. 


\section{Considerações finais}

A análise do Relatório de verificação das novas instalações do Ginásio Sagrado Coração possibilitou o levantamento de hipóteses das práticas culturais desenvolvidas pela instituição, assim como a compreensão de a utilização dos espaços e materiais, seguindo os padrões nacionalmente estabelecidos. Os princípios higienistas e científicos se apresentam com grande influência sobre todos os aspectos de constituição da instituição. Desde a construção do edifício e sua localização, perpassando pela distribuição das salas de aulas, das salas especiais e das demais dependências até a aquisição de materiais pedagógicos e artefatos industriais. Nesse contexto, o estudo dessa materialidade possibilita a apropriação dos significados e das condições historicamente construídas, as quais podem se apresentar de forma contraditórias, a depender da atuação e da ação dos sujeitos sobre os espaços e os materiais, em cada época.

Nas salas especiais relatadas pelo Inspetor Othoniel, os princípios do movimento de renovação/modernização da educação secundária brasileira podem ser constatados pelos aspectos da intencionalidade didática, compreendidos pelo método intuitivo e pela lição das coisas, com a utilização dos objetos pedagógicos que equipavam essas salas. Porém, não foi possível identificar a forma como estes objetos foram utilizados nas práticas culturais. $\mathrm{O}$ que podemos inferir é que a intencionalidade destas práticas de renovação no método de ensino estava presente, pois condizem com a forma vislumbrada tanto no colégio Pedro II, quanto no Colégio Arquidiocesano de São Paulo. Neste último caso, outro aspecto se destaca: a possibilidade de circulação/irradiação deste modelo na Rede de escolas da Ordem dos Maristas, da qual fazem parte a escola em São Paulo, e, certamente, influenciaram na Escola de Senhor do Bonfim - BA.

Para finalizar, o estudo aponta a necessidade de investigações mais aprofundadas com outros recortes temporais, a fim de ampliar o conhecimento sobre os usos dos espaços e do mobiliário e de sua repercussão nas práticas culturais no Ginásio Sagrado Coração.

\section{Referências}

ALCÂNTARA, W. R. R.;VIDAL, D. G. Corpo e matéria: relações (im)previsíveis da cultura material escolar. In: SILVA, V. L. G.; SOUZA, G.; CASTRO, C. A. 
(org.). Cultura material escolar em perspectiva histórica: escritas e possibilidades. Vitória: EDUFES, 2018, p. 235-260.

BENITO, B. E. Las materialidades de la escuela (a modo de prefacio). In: SILVA, V. L. G.; PETRY, M. G. (Orgs.). Objetos da escolar: espaços e lugares de constituição de uma cultura material escolar. Santa Catarina: Editora Insular, 2012, p.11-18.

BOCCHI, L. A. Espaço escolar e ciências: relações entre as prescrições governamentais e o ensino. RIDPHE_R Revista Iberoamericana do Patrimônio Histórico-Educativo, v. 6, n. 00, p. e020004, 3 jun. 2020. Disponível em: https://econtents.bc.unicamp.br/inpec/index.php/ ridphe/article/view/12304/8927. Acesso em: 17 jun. 2020

CASTRO, R. X.A.; SILVA, V. L. G. Cultura Material da Escola: entram em cena as carteiras. Educar em Revista, [S.I.], v. 27, n. 39, p. p. 207-224, apr. 2011. ISSN 1984-0411. Disponível em: https://revistas.ufpr.br/educar/article/ view/15080. Acesso em: 10 jul. 2020.

COSTA, P. C.. Apresentar o Brasil aos brasileiros, aproximar os brasileiros de sua pátria: a materialidade na geografia escolar de Delgado de Carvalho. Estud. hist. (Rio J.), Rio de Janeiro, v. 24, n. 48, p. 265-283, Dec. 2011. Disponível em: https://www.scielo.br/scielo.php?script=sci_ arttext\&pid=S0103-21862011000200002. Acesso em: 10 jul. 2020.

GINÁSIO SAGRADO CORAÇÃO. Estatutos do Ginásio Sagrado Coração. Com aprovação eclesiástica em 30 de novembro de 1944.

MENDONÇA, A. W.. P. C. et al. A criação do Colégio de Pedro ll e seu impacto na constituição do magistério público secundário no Brasil. Educ. Pesqui., São Paulo, v. 39, n. 4, p. 985-1000, dez. 2013. Disponível em: https://doi. org/10.1590/S1517-97022013000400011. Acesso em: 10 jul. 2020

MOGARRO, M. J. Arquivos e educação a construção da memória educativa. In: Revista Brasileira de História da Educação, n. 10, jul./ dez. 2005. Disponível em: http://periodicos.uem.br/ojs/index.php/rbhe/ article/view/38647/20178. Acesso em: 20 jun. 2020.

MOURA, O. A. Relatório de verificação das novas instalações do Ginásio Sagrado Coração. Senhor do Bonfim, Bahia, 1951.

ROCHA, H. H. P. Higienismo e cultura material escolar: notas sobre a invenção dos objetos e de suas funções. In: SILVA, V. L. G.; SOUZA, 
G.; CASTRO, C. A. (Orgs.). Cultura material escolar em perspectiva histórica: escritas e possibilidades. Vitória: EDUFES, 2018, p. 208-234.

VINÃO FRAGO, A. Espaços, usos e funções: a localização e disposição física da direção escolar na escola graduada. In: BENCOSTTA, M. L. A. (Org.). História da educação, arquitetura e espaço escolar. São Paulo: Cortez, 2005. p.15-47.

Recebido em: julho/2020

Aceito em: setembro/2020 